\title{
ISOLATES OF SARCOCYSTIS FALCATULA-LIKE ORGANISMS FROM SOUTH AMERICAN OPOSSUMS DIDELPHIS MARSUPIALIS AND DIDELPHIS ALBIVENTRIS FROM SÃO PAULO, BRAZIL
}

\author{
Author(s): J. P. Dubey , D. S. Lindsay, B. M. Rosenthal , C. E. Kerber , N. Kasai , H. F J. Pena , O. C H.
} Kwok, S. K. Shen, and S. M. Gennari

Source: Journal of Parasitology, 87(6):1449-1453. 2001.

Published By: American Society of Parasitologists

DOI: http://dx.doi.org/10.1645/0022-3395(2001)087[1449:IOSFLO]2.0.CO;2

URL: http://www.bioone.org/doi/full/10.1645/0022-3395\%282001\%29087\%5B1449\%3AIOSFLO

$\% 5 \mathrm{D} 2.0 . \mathrm{CO} \% 3 \mathrm{~B} 2$

BioOne (www.bioone.org) is a nonprofit, online aggregation of core research in the biological, ecological, and environmental sciences. BioOne provides a sustainable online platform for over 170 journals and books published by nonprofit societies, associations, museums, institutions, and presses.

Your use of this PDF, the BioOne Web site, and all posted and associated content indicates your acceptance of BioOne's Terms of Use, available at www.bioone.org/page/terms_of_use.

Usage of BioOne content is strictly limited to personal, educational, and non-commercial use. Commercial inquiries or rights and permissions requests should be directed to the individual publisher as copyright holder. 


\title{
ISOLATES OF SARCOCYSTIS FALCATULA-LIKE ORGANISMS FROM SOUTH AMERICAN OPOSSUMS DIDELPHIS MARSUPIALIS AND DIDELPHIS ALBIVENTRIS FROM SÃO PAULO, BRAZIL
}

\author{
J. P. Dubey, D. S. Lindsay ${ }^{\star}$, B. M. Rosenthal, C. E. Kerber†, N. Kasai†, H. F. J. Penał, O. C. H. Kwok, S. K. Shen, and \\ S. M. Gennarił \\ United States Department of Agriculture, Agricultural Research Service, Animal and Natural Resources Institute, Parasite Biology, \\ Epidemiology and Systematics Laboratory, Building 1001, Beltsville, Maryland 20705-2350. e-mail: jdubey@anri.barc.usda.gov
}

\begin{abstract}
Isolates of Sarcocystis falcatula-like organisms from South American opossums were characterized based on biological and morphological criteria. Sporocysts from intestinal scrapings of 1 Didelphis marsupialis and 8 Didelphis albiventris from São Paulo, Brazil, were fed to captive budgerigars (Melopsittacus undulatus). Budgerigars fed sporocysts from all 9 isolates became ill and $S$. falcatula-like schizonts were identified in sections of their lungs by immunohistochemical staining. Sarcocystis falcatula-like organisms were cultured from lungs of budgerigars fed sporocysts from D. marsupialis and from lungs of budgerigars fed sporocysts from 3 of $8 \mathrm{D}$. albiventris. The 33/54 locus amplified by polymerase chain reaction from culture-derived merozoites contained both a HinfI endonuclease recognition site previously suggested to diagnose $S$. falcatula and a DraI site thought to diagnosed $S$. neurona. Development of the isolate from $D$. marsupialis was studied in cell culture; its schizonts divided by endopolygeny, leaving a residual body. Morphological and genetic variation differentiated this Sarcocystis isolate originating in D. marsupialis from the Cornell 1 isolate of $S$. falcatula. This is the first report of a $S$. falcatula infection in the South American opossum, D. marsupialis.
\end{abstract}

Sarcocystis falcatula (Stiles, 1893) causes severe disease to certain avian species. Several outbreaks of acute pulmonary sarcocystosis have been observed among species of Psittaciformes and Passeriformes from zoos in North America (Jacobson et al., 1984; Clubb et al., 1986; Smith, Craig et al., 1990; Hillyer et al., 1991; Clubb and Frenkel, 1992; Mirandé et al., 1992; Page et al., 1992; Dubey, Garner et al., 2001). Experimentally, feeding even a few sporocysts can be lethal to certain avian species (Box and Smith, 1982; Dubey, 2000). Sarcocystis falcatula is considered an unusual species of Sarcocystis because of its wide intermediate host range (Passeriformes, Psittaciformes, Columbiformes) and its prolonged schizogony (lasting up to 5 mo) (Smith et al., 1987a, 1987b; Neill et al., 1989; Smith, Neill et al., 1990).

The North American opossum Didelphis virginiana serves as a definitive host (Box and Duszynski, 1978; Duszynski and Box, 1978; Box and Smith, 1982; Box et al., 1984). Until 1995, $S$. falcatula was considered the sole species to use $D$. virginiana as its definitive host. Recently, however, D. virginiana was found to be a definitive host for 2 additional nominal species of Sarcocystis: S. neurona (Dubey and Lindsay, 1998) and $S$. speeri (Dubey and Lindsay, 1999). Differentiation of these species was based on differences identified in their life cycles.

A genetic locus, termed 33/54, has been proposed to encompass variation enabling the differential diagnosis of $S$. neurona and $S$. falcatula by means of polymerase chain reaction (PCR) amplification and restriction endonuclease digestion (Tanhauser et al., 1999). The PCR products from several isolates of $S$. neurona were cut into 884- and 216-bp fragments by DraI, whereas other isolates presumed to represent $S$. falcatula were

Received 16 March 2001; revised 11 June 2001; accepted 11 June 2001. * Center for Molecular Medicine and Infectious Diseases, Department of Biomedical Sciences and Pathobiology, Virginia-Maryland Regional College of Veterinary Medicine, Virginia Tech, 1410 Prices Fork Road, Blacksburg, Virginia 24061-0342.

† Paddock Laboratòrio de Análiases, Clínicas Veterinárias, Rua Pero Leão, 149-CEPO5423-060, São Paulo, Brazil.

\$Faculdade de Medicina Veterinária e Zootecnia da Universidade de São Paulo, Av. Prof. Dr. Orlando Marques de Paiva, 87, CEP 05508, São Paulo, Brazil. not; conversely, HinfI failed to cut the products of S. neurona, but did cut those from $S$. falcatula into 745- and 355-bp fragments (Tanhauser et al., 1999). Using this system to characterize 9 isolates of sporocysts from $D$. virginiana feces, 5 corresponded to the $S$. neurona pattern, 2 corresponded to the $S$. falcatula pattern, but 2 were found to be cut by each of the 2 restriction endonucleases (Tanhauser et al., 1999).

Although these $S$. falcatula-like parasites have begun to be characterized in $D$. virginiana, the single opossum species endemic to the continental United States, less is known about the diversity and distribution of such parasites among the several species of opossum endemic to Central and South America. Sarcocystis falcatula-like parasites have been described in the South American opossum Didelphis albiventris from Argentina and from Brazil (Dubey, Venturini et al., 1999; Dubey, Lindsay, Venturini, and Venturini, 2000; Dubey, Lindsay, Rezende, and Costa, 2000). The S. falcatula-like parasites from Argentina, when assayed at the 33/54 locus, were found to contain both the DraI site thought to characterize $S$. neurona, as well as the HinfI site thought to diagnose $S$. falcatula. In contrast, the Brazilian isolate contained solely the DraI site (Dubey, Lindsay, Rezende, and Costa, 2000). To further evaluate the faunal diversity for Sarcocystis spp. among South American Didelphidae, we studied the morphological and molecular attributes of parasites obtained as sporocysts from 1 Didelphis marsupialis and $8 \mathrm{D}$. albiventris, whose capacity to infect birds and failure to infect mice suggested their identity was $S$. falcatula.

\section{MATERIALS AND METHODS}

\section{Parasite sources}

As part of a project to characterize isolates of $S$. falcatula-like organisms in opossums, Sarcocystis sporocysts were obtained from scrapings of $1 \mathrm{D}$. marsupialis and $8 \mathrm{D}$. albiventris intestine, as described by Dubey, Kerber et al. (2000) and Dubey, Lindsay, Kerber et al. (2001). Sporocysts from all opossums were initially fed to budgerigars (Melosittacus undulatus) and gamma interferon gene knockout (KO) mice to distinguish $S$. falcatula from $S$. neurona and $S$. speeri; $S$. falcatula is lethal to budgerigars but is not infective to KO mice (Marsh et al., 1997; Dubey and Lindsay, 1998), and S. neurona and S. speeri are lethal to KO mice but not infective to budgerigars (Dubey and Lindsay, 1998, 1999). Details of infections attributed to $S$. speeri and $S$. neurona from 
TABLE I. Summary of Sarcocystis falcatula-like isolates from opossums from São Paulo, Brazil.

\begin{tabular}{|c|c|c|c|c|c|c|}
\hline Didelphis sp. & $\begin{array}{l}\text { Op- } \\
\text { os- } \\
\text { sum } \\
\text { no. }\end{array}$ & $\begin{array}{c}\text { Ex- } \\
\text { peri- } \\
\text { ment } \\
\text { no. }\end{array}$ & Bird no. & $\begin{array}{l}\text { Died/ } \\
\text { killed* }\end{array}$ & $\begin{array}{c}\text { Cell } \\
\text { culture } \dagger\end{array}$ & $\begin{array}{c}\text { RFLP } \\
\text { analysis } \\
\text { of } 33 / 54 \\
\text { locus } \ddagger\end{array}$ \\
\hline \multirow[t]{8}{*}{ D. marsupialis } & \multirow[t]{8}{*}{14} & \multirow[t]{2}{*}{86} & 182 & D14 & BT- & ND \\
\hline & & & 183 & K11 & ND & ND \\
\hline & & \multirow[t]{2}{*}{89} & 187 & D9 & BT- & ND \\
\hline & & & 188 & D9 & ND & ND \\
\hline & & \multirow[t]{4}{*}{90} & 151B & K8 & ND & ND \\
\hline & & & $152 \mathrm{~B}$ & K10 & M617+ & ND \\
\hline & & & 199 & D10 & $\mathrm{BT}+$ & Yes \\
\hline & & & 200 & K10 & $\mathrm{BT}+$ & Yes \\
\hline \multirow[t]{20}{*}{ D. albiventris } & \multirow[t]{2}{*}{15} & \multirow[t]{2}{*}{86} & 176 & DK9 & ND & ND \\
\hline & & & 173 & DK9 & $\mathrm{BT}+$ & Yes \\
\hline & \multirow[t]{2}{*}{16} & \multirow[t]{2}{*}{86} & 175 & D9 & ND & ND \\
\hline & & & 174 & K9 & $\mathrm{BT}+$ & Yes \\
\hline & \multirow[t]{2}{*}{16} & \multirow[t]{2}{*}{86} & 175 & D9 & ND & ND \\
\hline & & & 174 & K9 & $\mathrm{BT}+$ & Yes \\
\hline & \multirow[t]{4}{*}{17} & \multirow[t]{2}{*}{89} & 189 & DK8 & $\mathrm{BT}$ & ND \\
\hline & & & 190 & D8 & ND & ND \\
\hline & & \multirow[t]{2}{*}{90} & $157 \mathrm{~B}$ & K8 & $\mathrm{EK}+$ & ND \\
\hline & & & 158B & K8 & M617+ & ND \\
\hline & \multirow[t]{2}{*}{18} & \multirow[t]{2}{*}{89} & 191 & D9 & $\mathrm{BT}+$ & ND \\
\hline & & & 192 & D9 & $\mathrm{BT}+$ & ND \\
\hline & \multirow[t]{2}{*}{19} & \multirow[t]{2}{*}{89} & 185 & K18 & $\mathrm{EK}+$ & ND \\
\hline & & & 186 & D18 & $\mathrm{EK}-$ & ND \\
\hline & \multirow[t]{2}{*}{20} & \multirow[t]{2}{*}{89} & 193 & D13 & $\mathrm{EK}+$ & ND \\
\hline & & & 194 & K13 & $\mathrm{BT}+$ & Yes \\
\hline & \multirow[t]{2}{*}{21} & \multirow[t]{2}{*}{90} & 155 & K18 & $\mathrm{BT}+$ & ND \\
\hline & & & 156 & K8 & ND & ND \\
\hline & \multirow[t]{2}{*}{23} & \multirow[t]{2}{*}{90} & 153 & DK10 & M617 & ND \\
\hline & & & 154 & K8 & $\mathrm{BT}+$ & ND \\
\hline
\end{tabular}

* D, died; K, killed; DK, killed when sick.

$\uparrow \mathrm{T}$, bovine turbinate; EK, equine kidney; M617, bovine monocyte; ND, not done; + , parasites cultivated; - , parasites not cultivated. $\doteqdot \mathrm{ND}$, not done.

these 9 opossums were reported earlier (Dubey, Kerber et al., 2000; Dubey, Lindsay, Kerber et al., 2001). The present paper discusses exclusively those parasites diagnosed as $S$. falcatula-like on the basis of this bioassay.

\section{Sporocysts and bioassay}

Sarcocystis sp. sporocysts were obtained from 9 adult opossums submitted to the Universidade de São Paulo, Brazil, in November and December 1999 (Table I). These opossums inhabited the vicinity of São Paulo. The intestines were removed and the epithelium was scraped from the small intestine into a blender, homogenized, and digested in a $10 \%$ solution of commercial bleach for $10 \mathrm{~min}$. After centrifugation to remove bleach, the suspension was filtered through a series of metal sieves (final exclusion $400 \mu \mathrm{m}$ ), and the sporocysts and debris were concentrated by centrifugation. The resulting material was stored in Hanks balanced salt solution (HBSS) containing $10 \mathrm{mg} / \mathrm{ml}$ streptomycin, $10,000 \mathrm{U} / \mathrm{ml}$ penicillin, $500 \mathrm{U} / \mathrm{ml}$ mycostatin, and $0.5 \mathrm{mg} / \mathrm{ml}$ fungizone (Dubey et al., 1989). Sporocysts were shipped via air from São Paulo, Brazil, to Beltsville, Maryland. Sporocysts were stored at $4 \mathrm{C}$ until used in the present studies. At Beltsville, sporocysts were bioassayed in KO mice (BALB/c-Ifng ${ }^{\text {tmlTs }}$ ) to test for S. neurona and S. speeri infections as described (Dubey, Kerber et al., 2000; Dubey, Lindsay, Kerber et al., 2001).

For testing the infectivity of sporocysts, 10-20-wk-old budgerigars raised in captivity were obtained from a local aviary (Dubey and Lindsay, 1998). The sporocysts were deposited in the crops of birds via a feeding needle (Table I). Two uninoculated birds were kept as controls. The birds were housed in an isolation building and were given sterilized water and bird feed.

\section{Histologic and immunohistochemical examinations}

Animals that were killed or that died were necropsied. Portions of major organs were fixed in $10 \%$ buffered formalin and processed for histology. Paraffin-embedded sections were cut at $5 \mu \mathrm{m}$ and examined after staining with hematoxylin and eosin. For immunohistochemical staining, paraffin sections were reacted with anti-S. falcatula antibodies. Polyclonal serum from a rabbit immunized with the Cornell 1 strain of S. falcatula was used as the antiserum (Dubey, 2000; Dubey, Garner et al., 2001).

\section{In vitro cultivation}

African green monkey (Cercopithecus aethiops) kidney cells (CV-1 cells, ATTC CCL-70, American Type Culture Collection, Rockville, Maryland) and bovine turbinate cells (BT cells, ATTC CRL 1390) were used as host cells. The host cells were grown to confluence in $25-\mathrm{cm}^{2}$ plastic cell culture flasks in growth media consisting of $10 \%(\mathrm{v} / \mathrm{v})$ fetal bovine serum (FBS) in RPMI 1640 medium supplemented with penicillin $\mathrm{G}$ at $100 \mathrm{U} / \mathrm{ml}$ and with streptomycin at $100 \mathrm{mg} / \mathrm{ml}$. Cell cultures are maintained in growth medium in which the FBS content was lowered from $10 \%$ to $2 \%$. Cell cultures were incubated at $37 \mathrm{C}$ in a humidified atmosphere containing $5 \% \mathrm{CO}_{2}$ and $95 \%$ air.

For descriptive studies, merozoites from the isolate from budgerigar no. 200 (Table I) were harvested from infected cell cultures by removing the medium and replacing it with HBSS without calcium and magnesium. The BT cells were then removed from the plastic growth surface by use of a cell scraper. This cell mixture was passed through a 27-gauge needle attached to a 10-ml syringe to rupture host cells. The suspension was then filtered through a sterile $3-\mu \mathrm{m}$ filter to remove cellular debris. The numbers of merozoites in the filtrate were determined using a hemacytometer. The merozoites were inoculated onto 22$\mathrm{mm}^{2}$ glass coverslips containing a monolayer of CV-1 or BT cells in 6welled tissue culture plates. Coverslips were removed on $1-8,10$, and 11 days postinoculation (PI), fixed in $10 \%$ phosphate-buffered formalin for $30 \mathrm{~min}$, placed in $100 \%$ methanol for $10 \mathrm{~min}$, and stained with a Giemsa type stain. Coverslips were attached to glass microscope slides with Permount (Fisher Scientific, Fair Lawn, New Jersey) and examined with light microscopy. Developmental stages $(n=20)$ in CV-1 cells were measured with a calibrated ocular micrometer. Measurements are expressed as the mean followed by the range in parenthesis.

\section{Molecular characterization}

To preliminarily characterize the organisms newly isolated from $D$. albiventris, they were compared to other isolates of Sarcocystis spp. by means of a PCR amplification and restriction endonuclease digestion assay previously described by Tanhauser et al. (1999). DNA was extracted from merozoites that had been frozen at $-20 \mathrm{C}$ after harvest from infected CV-1 cells and subjected to PCR amplification using primers JNB33 (5'-CGAACAGAGATGAGGAAAAT-3') and JNB54 (5'-GTTGTGGTGTTGCGTGAGTC-3') initially described by Tanhauser et al. (1999). These amplification products were subsequently subjected to restriction endonucleases DraI and HinfI run on a $1 \%$ agarose gel. These were compared to other parasite isolates resembling $\mathrm{S}$. falcatula: the SF-1A from budgerigar no. 62 of Dubey, Lindsay, Venturini, and Venturini (2000), an organism isolated from Jabotical, Brazil (bird no. 100 isolate described in Dubey, Lindsay, Rezende, and Costa, 2000; Dubey, Rosenthal, and Speer, 2001), and the Cornell 1 strain of $S$. falcatula (Lindsay et al., 1999; Marsh et al., 1999). Two of these isolates (SF-1A, Cornell 1) were cloned by limiting dilution as described by Rosenthal et al. (2001). Two budgerigars (nos. 213, 217) were inoculated subcutaneously with $\sim 10^{7}$ merozoites of the isolate of S. falcatula recovered in culture from the lungs of budgerigar no. 200 (derived from D. marsupialis). Both budgerigars died of pulmonary sarcocystosis 9 days later. Lung homogenates from budgerigar no. 213 were used for sequencing studies. For comparative purposes, an S. neurona isolate (SN6 of Dubey, Matson et al., 1999) that had been cloned by limiting dilution was also assayed in this way.

The large subunit (LSU) rDNA, the ITS-1 locus, and a locus of unknown location 25/396 were amplified by PCR from the D. marsupialis 

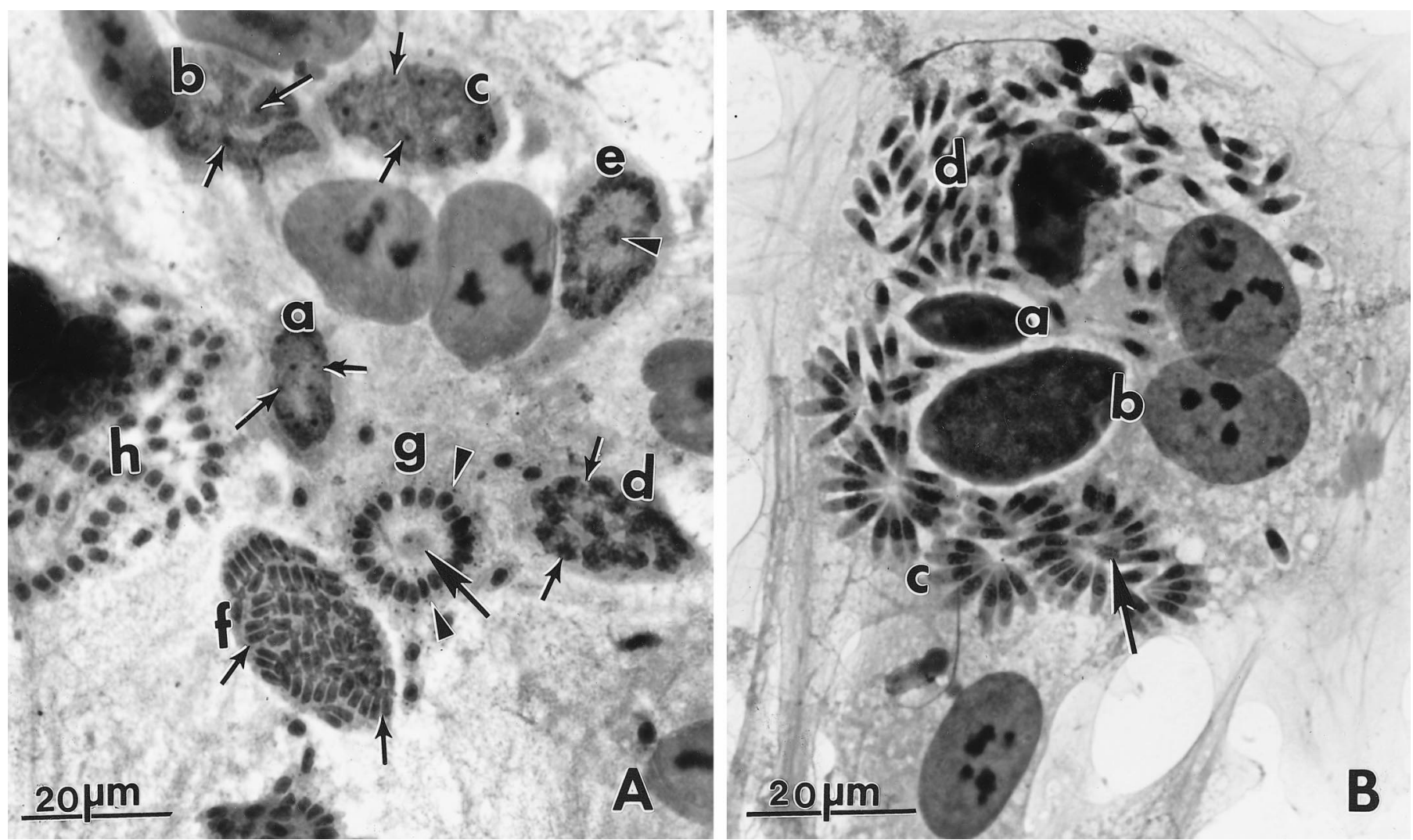

FIGURE 1. Development of a Sarcocystis falcatula-like parasite from Didelphis marsupialis in bovine turbinate cells. Giemsa stain. A. a-c, nucleus of schizont dividing into nuclear lobes with visible nucleoli (arrows); d, nucleus dividing into nuclear lobes, connected by nuclear stands (arrows); e, nuclear lobes arranged peripherally with a central residual-like body (arrowhead); f, nuclear lobes (arrows) arranged in groups; g, schizont with peripherally arranged merozoites (arrowheads) and a residual body (arrow); h, extracellular merozoites. B. Two immature schizonts (a, b); groups of mature schizonts (c), 1 with a residual body (arrow); and free merozoites (d).

isolate, directly sequenced by previously described means, and compared to all available homologs (Marsh et al., 1999; Tanhauser et al., 1999; Rosenthal et al., 2001).

\section{RESULTS}

Budgerigars fed sporocysts from all 9 opossums became ill and were killed or died by day 19 PI. Sarcocystis falcatulalike schizonts were found in lungs of all 26 budgerigars; these schizonts reacted positively with anti-S. falcatula polyclonal rabbit serum. Two control budgerigars remained clinically normal and protozoa were not detected in their tissues when examined 28 days PI.

Schizonts and merozoites were cultured from lungs of budgerigars fed sporocysts from each of the 9 opossums; these organisms resembled $S$. falcatula, but their development was not studied in detail. No structural differences were noted in developmental stages. The morphological development of organisms cultured from the lung of budgerigar no. 200, fed sporocysts from $D$. marsupialis no. 14 , is considered representative. Merozoites entered CV-1 and BT cells and underwent schizogony within 3 days (Fig. 1). Merozoites were usually located next to the host cell nucleus. Intracellular merozoites and developing schizonts were seen on days 1 and 2 PI (Fig. 1A). Development and schizont nuclear division was asynchronous, resulting in cells containing structurally different organisms. Schizonts retained their elongate merozoite shape during development. Schizonts with mature merozoites were seen on days postinoculation but were more numerous 4 days PI. Merozoites formed peripherally and often were around a residual body (Fig. 1B). Merozoites present at 4 days PI measured 5.7 by $1.6 \mu \mathrm{m}(4.8-7.2$ by $1.2-1.6 \mu \mathrm{m}, \mathrm{n}=20)$. Maturing schizonts with condensing nuclei measured 26.0 by $13.6 \mu \mathrm{m}$ (22.4-29.6 by $11.2-16.0 \mu \mathrm{m}, \mathrm{n}=20) 4$ days PI. No additional developmental types were noted on the remaining observation days postinoculation.

Enough merozoites were available from cultures derived from 4 opossums (nos. 14, 15, 16, 20) to perform PCR amplification of the 33/54 locus (Fig. 2). The pattern of products produced by restriction digestion with DraI and HinfI of the parasites isolated from $D$. marsupialis were representative and were identical to that of SF-1A isolate (bird no. 62) in D. albiventris from Argentina and distinct from the SN6 isolate of $S$. neurona, the cloned Cornell 1 strain of S. falcatula, and bird no. 100 from Jabotical, Brazil.

The parasites derived from D. marsupialis were identical in sequence to the Cornell 1 strain of S. falcatula (Lindsay et al., 1999) and the SF-1A Argentine isolate (bird no. 62) in D. albiventris (Dubey, Lindsay, Venturini, and Venturini, 2000) at the 25/396 locus. In contrast, the ITS- 1 sequenced from this $D$. marsupialis isolate contained unique substitutions but shared other substitutions heretofore found elsewhere only in UCD01 and the Cornell 2 isolates, but not in the Cornell 1 or Florida 


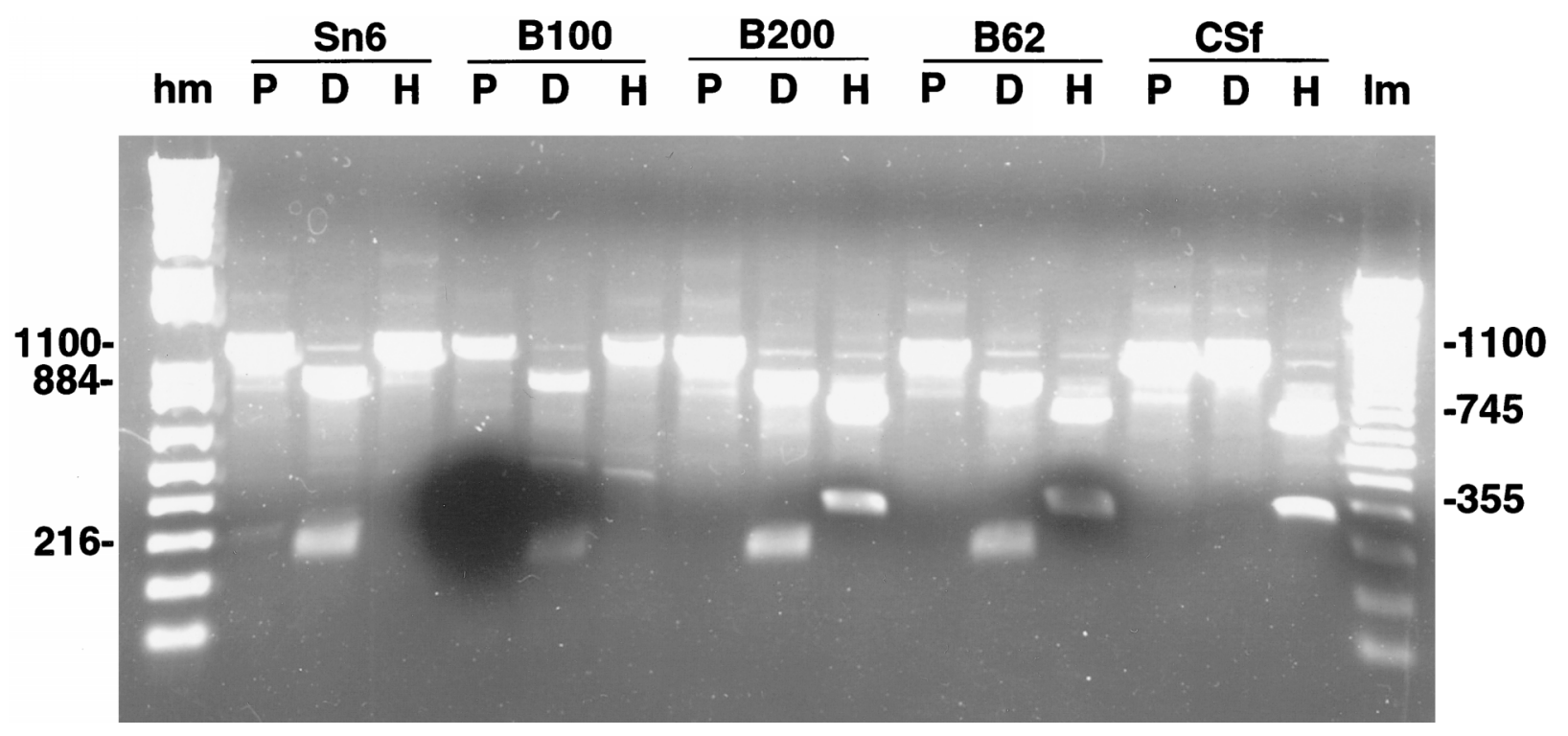

FIGURE 2. Results of PCR (P) followed by $\operatorname{DraI}(\mathrm{D})$ and $\operatorname{HinfI}(\mathrm{H})$ restriction enzyme digestion of merozoite DNA obtained from merozoites of Sarcocystis neurona strain 6 (SN6), bird no. 100 (B100), bird no. 200 (B200), bird no. 62, and the Cornell 1 strain S. falcatula (Csf), hm, high-molecular mass marker; lm, low-molecular mass marker.

1 isolates of $S$. falcatula or in any of several exemplars of $S$. neurona described previously (Marsh et al., 1999). A single substitution differentiates this isolate in D. marsupialis from the Cornell 1 strain of $S$. falcatula over a span of the LSU rRNA gene that also differentiates $S$. neurona by a single substitution. To provide some context, several substitutions uniquely distinguish $S$. speeri at this highly conserved locus when it is compared to homologous sequences in S. falcatula and S. neurona. The ITS-1, 25/396, and LSU rRNA sequences have been deposited in GenBank (AF399339, AF389340, and AF389341, respectively).

\section{DISCUSSION}

Although accurate identification of parasites belonging to this group is hampered by a paucity of recognized genetic variation and the imperfect correspondence of variation in each locus, it can be concluded that $D$. marsupialis serve as a definitive host for parasites that are capable of infecting experimental avian hosts and that can also be distinguished from $S$. neurona and $S$. speeri on the basis of morphological and molecular characteristics. Their close relationship to, but evident distinction from, previously reported isolates identified as $S$. falcatula provides further indication that this taxon is diverse and perhaps consists of more than 1 species (Marsh et al., 1999; Tanhauser et al., 1999; Rosenthal et al., 2001).

Neither restriction endonuclease digestion of the 33/54 locus nor sequencing of the 25/396 locus distinguished the $S$. falcatula-like isolate (from D. marsupialis from São Paulo, Brazil) from previously reported isolates of $S$. falcatula-like isolates (from D. albiventris from Argentina; SF-1A and SF-2A of Dubey, Lindsay, Venturini, and Venturini, 2000). At least 3 isolates from $D$. albiventris from São Paulo, Brazil (from opossum nos. 15,16 , and 20 of this study), appear similar to the 2 isolates from $D$. albiventris from Argentina on the basis of restriction endonuclease digestion of the 33/54 locus. Nonetheless, D. marsupialis and D. albiventris-derived South American isolates differ by a small number of substitutions in the ITS-1 locus and by a single change in the LSU rDNA.

Budgerigars often die before sarcocysts are produced in experimental infections, and even those birds that survive infection may not develop mature sarcocysts (Box et al., 1984). Consequently, little data are available on the extent or nature of morphological variation among tissue stages of $S$. falcatula-like parasites. This limitation underscores the need for reliable molecular diagnostic tools but also hampers progress toward that goal. A full accounting of the diversity of this parasite fauna and the relationships among its members may require identification of experimental hosts for whom disease is more limited.

Both $D$. albiventris and $D$. marsupialis are widely distributed in South and Central America, yet clinical pulmonary sarcocystosis among avian species has not been reported from this region. Results of the present and previous studies indicate, however, that $S$. falcatula-like parasites are prevalent. Natural avian infections might escape notice if they are generally asymptomatic. Alternatively, rapid scavenging of dead avian hosts may render natural mortality difficult to identify. Prevalent infection among widespread opossum species nonetheless underscores the risk to which birds, especially those in zoos, may be exposed.

\section{LITERATURE CITED}

Box, E. D., AND D. W. DuszYnSKI. 1978. Experimental transmission of Sarcocystis from icterid birds to sparrows and canaries by sporocysts from the opossum. Journal of Parasitology 64: 682-688. , AND J. H. SMITH. 1982. The intermediate host spectrum in a Sarcocystis species of birds. Journal of Parasitology 68: 668-673. , J. L. MeIER, AND J. H. SMith. 1984. Description of Sarcocystis falcatula Stiles, 1893, a parasite of birds and opossums. Journal of Protozoology 31: 521-524.

Clubb, S. L., AND J. K. FrenKel. 1992. Sarcocystis falcatula of opossums: Transmission by cockroaches with fatal pulmonary disease in Psittacine birds. Journal of Parasitology 78: 116-124. 
C. H. Gardiner, And D. L. Graham. 1986. An acute fatal illness in old world psittacine birds associated with Sarcocystis falcatula of opossums. Annual Proceedings Association of Avian Veterinarians. 139-149.

Dubey, J. P. 2000. Prevalence of Sarcocystis species sporocysts in wild caught opossums (Didelphis virginiana). Journal of Parasitology 86: 705-710.

, M. M. Garner, M. D. Stetter, A. E. Marsh, and B. C. Barr. 2001. Acute Sarcocystis falcatula-like infection in a carmine beeeater (Merops nubicus) and immunohistochemical cross reactivity between S. falcatula and Sarcocystis neurona. Journal of Parasitology. In press.

, C. E. Kerber, D. S. Lindsay, N. Kasai, and H. F. J. Pena. 2000. The South American opossum Didelphis marsupialis, from Brazil as another definitive host for Sarcocystis speeri Dubey and Lindsay, 1999. Parasitology 121: 589-594.

, AND D. S. LiNDSAY. 1998. Isolation in immunodeficient mice of Sarcocystis neurona from opossum (Didelphis virginiana) feces, and its differentiation from Sarcocystis falcatula. International Journal for Parasitology 28: 1823-1828.

, AND - 1999. Sarcocystis speeri n. sp. (Protozoa: Sarcocystidae) from the opossum (Didelphis virginiana). Journal of Parasitology 85: 903-909.

P. C. B. Rezende, And A. J. Costa. 2000. Characterization of an unidentified Sarcocystis falcatula-like parasite from the South American opossum, Didelphis albiventris from Brazil. Journal of Eukaryotic Microbiology 47: 538-544.

C. E. Kerber, N. Kasai, H. F. J. Pena, S. M. Gennari, O. C. H. Kwok, S. K. Shen, and B. M. Rosenthal. 2001. First isolation of Sarcocystis neurona from the South American opossum, Didelphis albiventris, from Brazil. Veterinary Parasitology 95: 295-304.

, D. E. Mattson, C. A. Speer, R. J. Baker, D. M. Mulrooney, S. J. Tornquist, A. N. Hamir, and T. C. Gerros. 1999. Characterization of Sarcocystis neurona isolate (SN6) from a naturally infected horse from Oregon. Journal of Eukaryotic Microbiology 46: 500-506.

, B. M. Rosenthal, And C. A. Speer. 2001. Sarcocystis lindsayi n. sp. (Protozoa: Sarcocystidae) from the South American opossum, Didelphis albiventris from Brazil. Journal of Eukaryotic Microbiology 48: 595-603.

C. A. SPEER, AND R. FAYER. 1989. Sarcocystosis of animals and man. CRC Press, Boca Raton, Florida, 215 p.

-, L. Venturini, C. Venturini, W. Basso, and J. UnZaga. 1999. Isolation of Sarcocystis falcatula from the South American opossum (Didelphis albiventris) from Argentina. Veterinary Parasitology 86: 239-244.

, AND C. A. SPEER. 2000. Isolation of Sarcocystis speeri Dubey and Lindsay, 1999 from the South American opossum (Didelphis albiventris) from Argentina. Journal of Parasitology 86: 160-163.

DusZynski, D. W., AND E. D. Box. 1978. The opossum (Didelphis virginiana) as a host for Sarcocystis debonei from cowbirds (Moloth- rus ater) and grackles (Cassidix mexicanus, Quiscalus quiscula). Journal of Parasitology 64: 326-329.

Hillyer, E. V., M. P. Anderson, E. C. Greiner, C. T. Atkinson, And J. K. FrENKEL. 1991. An outbreak of Sarcocystis in a collection of psittacines. Journal of Zoo and Wildlife Medicine 22: 434-445.

Jacobson, E. R., C. H. Gardiner, A. Nicholson, And C. D. Page. 1984. Sarcocystis encephalitis in a cockatiel. Journal of the American Veterinary Medical Association 185: 904-906.

Lindsay, D. S., J. P. Dubey, K. M. Horton, and D. D. Bowman. 1999. Development of Sarcocystis falcatula in cell cultures demonstrates that it is different from Sarcocystis neurona. Parasitology 118: 227-233.

Marsh, A. E., B. C. Barr, L. Tell, D. D. Bowman, P. A. Conrad, C. KetChERSIDE, AND T. GREEN. 1999. Comparison of the internal transcribed spacer, ITS-1, from Sarcocystis falcatula isolates and Sarcocystis neurona. Journal of Parasitology 85: 750-757.

- — - M. Koski, E. Greiner, J. Dame, And P. A. CONRAD. 1997. In vitro cultivation and experimental inoculation of Sarcocystis falcatula and Sarcocystis neurona merozoites into budgerigars (Melopsittacus undulatus). Journal of Parasitology 83: 1189-1192.

Mirandé, L. A., E. W. Howerth, And R. P. Poston. 1992. Chlamydiosis in a red-tailed hawk (Buteo jamaicensis). Journal of Wildlife Diseases 28: 284-287.

Neill, P. J. G., J. H. Smith, And E. D. Box. 1989. Pathogenesis of Sarcocystis falcatula (Apicomplexa: Sarcocystidae) in the budgerigar (Melopsittacus undulatus) IV. Ultrastructure of developing, mature and degenerating sarcocysts. Journal of Protozoology 36: 430-437.

Page, C. D., R. E. Schmidt, J. H. English, C. H. Gardiner, G. B. Hubbard, And G. C. Smith. 1992. Antemortem diagnosis and treatment of sarcocystosis in two species of psittacines. Journal of Zoo and Wildlife Medicine 23: 77-85.

Rosenthal, B. M., D. S. Lindsay, And J. P. Dubey. 2001. Relationships among Sarcocystis species transmitted by New World opossums (Didelphis spp.). Veterinary Parasitology 95: 133-142.

Smith, J. H., T. M. Craig, E. A. Dillard III, P. J. G. Neill, and L. P. JONES. 1990. Naturally occurring apicomplexan acute interstitial pneumonitis in thick-billed parrots (Rhynchopsitta pachyrhyncha). Journal of Parasitology 76: 285-288.

, J. L. Meier, P. J. G. NeILl, And E. D. Box. 1987a. Pathogenesis of Sarcocystis falcatula in the budgerigar. I. Early pulmonary schizogony. Laboratory investigation 56: 60-71. - , $\longrightarrow$, 1987b - Pathogenesis of Sarcocystis falcatula in the budgerigar. II. Pulmonary pathology. Laboratory Investigation 56: 72-84.

, P. J. G. Neill, E. A. Dillard III, And E. D. Box. 1990. Pathology of experimental Sarcocystis falcatula infections of canaries (Serinus canarius) and pigeons (Columba). Journal of Parasitology 76: $59-68$.

StILES, C. W. 1893. On the presence of sarcosporidia in birds. USDA Bureau of Animal Industries Bulletin 3: 79-89.

Tanhauser, S. M., C. A. Yowell, T. J. Cutler, E. C. Greiner, R. J. MACKAY, AND J. B. DAME. 1999. Multiple DNA markers differentiate Sarcocystis neurona and Sarcocystis falcatula. Journal of Parasitology 85: 221-228. 